14.1;06.1

\title{
Источники двухволнового узкополосного излучения на основе алмазных наночастиц с введенными одновременно центрами окраски германий-вакансия и кремний-вакансия
}

\author{
(C) С.А. Грудинкин ${ }^{1}$, Н.А. Феоктистов ${ }^{1}$, К.В. Богданов ${ }^{2}$, А.В. Баранов ${ }^{2}$, В.Г. Голубев ${ }^{1}$ \\ ${ }^{1}$ Физико-технический институт им. А.Ф. Иоффре РАН, Санкт-Петербург, Россия \\ ${ }^{2}$ Университет ИТМО, Санкт-Петербург, Россия \\ E-mail: grudink.gvg@mail.ioffe.ru
}

Поступило в Редакцию 27 марта 2020 г

В окончательной редакции 27 марта 2020 г.

Принято к публикации 31 мая 2020 г.

Методом химического газофазного осаждения с горячей нитью синтезированы алмазные частицы с центрами окраски германий-вакансия и кремний-вакансия. На следующем этапе проведено реактивное ионноплазменное травление частиц. В результате получены алмазные наночастицы, спектры фотолюминесценции которых состоят из двух узких интенсивных бесфононных линий введенных центров. Такие флуоресцентные алмазные наночастицы перспективны для применения в качестве источников двухволнового узкополосного излучения в люминесцентной нанотермометрии.

Ключевые слова: центр окраски германий-вакансия, центр окраски кремний-вакансия, алмазные наночастицы, нанотермометрия.

DOI: 10.21883/PJTF.2020.17.49892.18320

Алмазные наночастицы с оптическими центрами окраски представляют интерес для создания наноразмерных оптических сенсоров с целью измерения локальных изменений температуры на клеточном уровне в биологических тканях [1-6]. Это обусловлено уникальными свойствами наноалмазов: биосовместимостью, химической стойкостью, возможностью проведения функционализации поверхности. Важно, что центры окраски в наноалмазах обладают стабильной и яркой фотолюминесценцией (ФЛ) [7,8].

Для люминесцентной нанотермометрии перспективными являются алмазные наночастицы с центрами окраски, включающими междоузельный атом IV группы $(\mathrm{Si}, \mathrm{Ge}, \mathrm{Sn})$ и две ближайшие вакансии $(V)$ в соседних узлах решетки [3-6]. Достоинство этих центров состоит в том, что интегральная интенсивность их ФЛ сосредоточена в основном в одной узкой бесфононной линии (БФЛ) [8]. Метод регистрации температуры с использованием сенсоров на основе алмазных наночастиц с центрами окраски основывается на мультипараметрическом анализе температурной зависимости формы и спектрального положения БФЛ центра окраски [5].

Преимуществом центра $\mathrm{Ge} V$ является близкий к единице квантовый выход сигнала ФЛ, что позволяет использовать небольшие мощности излучения и тем самым минимизировать эффекты локального разогрева из-за взаимодействия оптического излучения с биологическими тканями [4].

Центр Si $V$ обладает большей (по сравнению с центром Ge $V$ ) чувствительностью при измерении сдвига максимума БФЛ при изменении температуры $(\Delta \lambda / \Delta T \sim 0.012 \mathrm{~nm} / \mathrm{K}$ для $\operatorname{Si} V$ и $\sim 0.009 \mathrm{~nm} / \mathrm{K}$ для
$\operatorname{Ge} V)$ [3,6]. Максимум БФЛ центра окраски $\operatorname{Si} V$ находится в окне прозрачности биологических тканей и не перекрывается со спектральным диапазоном их автофлуоресценции, что позволяет проводить измерения при небольших мощностях излучения и таким образом минимизировать перегрев и фотоиндуцированные изменения биологических объектов [2].

В настоящей работе синтез алмазных наночастиц с одновременно введенными центрами Ge $V$ и $\mathrm{Si} V$ проводился в два этапа. На первом этапе алмазные частицы выращивались методом химического газофазного осаждения с горячей нитью (HFCVD) [9], в процессе которого осуществлялось легирование германием и кремнием. На втором этапе алмазные частицы были подвергнуты реактивному ионно-плазменному травлению [10].

Алмазные частицы синтезированы на подложке кристаллического кремния в газовой смеси $\mathrm{CH}_{4} / \mathrm{H}_{2}$. Параметры процесса HFCVD следующие: температура вольфрамовой спирали $2000-2200^{\circ} \mathrm{C}$, рабочее давление в реакторе 40 Torr, расход водорода $500 \mathrm{sccm}$, концентрация метана в газовой смеси 2-6\%, температура подложки $720^{\circ} \mathrm{C}$, время роста алмазных частиц $2 \mathrm{~h}$. В качестве центров зародышеобразования использовались наноалмазы детонационного синтеза с характерным размером $\sim 4 \mathrm{~nm}$, которые методом аэрозольного распыления наносились на подложку [11]. Концентрация наноалмазов детонационного синтеза на поверхности подложки составляла $10^{6}-10^{7} \mathrm{~cm}^{-2}$. Источником атомов $\mathrm{Si}$ служила подложка кристаллического кремния, а источником атомов $\mathrm{Ge}$ - расположенная рядом с ней на держателе подложек пластина кристаллического германия. Травление твердотельных источников $\mathrm{Ge}$ и $\mathrm{Si}$ 
атомарным водородом приводит к появлению летучих радикалов $\mathrm{GeH}_{x}$ и $\mathrm{SiH}_{x}$. Перенос и осаждение этих радикалов на поверхность растущих алмазных частиц с последующим вхождением $\mathrm{Ge}$ и $\mathrm{Si}$ в решетку алмаза обусловливают образование центров окраски.

На рис. 1 показаны спектры комбинационного рассеяния света (КРС) алмазных частиц, полученных при концентрации метана в газовой смеси 2, 4 и 6\%. Размер синтезированных при концентрации метана $4 \%$ отдельных алмазных частиц составил $\sim 700 \mathrm{~nm}$ (см. вставку на рис. 1). Измерения спектров КРС и ФЛ проводились для отдельной частицы при комнатной температуре с помощью микрорамановского спектрометра Renishaw InVia Raman Microscope c конфокальным микроскопом (спектральное разрешение $\sim 1 \mathrm{~cm}^{-1}$ ). При измерениях использовалась длина волны возбуждающего излучения лазера $488 \mathrm{~nm}$. В спектрах КРС регистрировалась линия вблизи $1332 \mathrm{~cm}^{-1}$ (рис. 1), которая соответствует ТОфонону симметрии $F_{2 g}$ в решетке алмаза (линия алмаза) и указывает на присутствие кристаллической алмазной фазы [12]. Ширина на половине высоты (FWHM) этой линии увеличивается с ростом концентрации метана в газовой смеси с $\sim 6$ до $\sim 8 \mathrm{~cm}^{-1}$, что свидетельствует об уширении распределения величин внутренних напряжений в алмазных кристаллитах [10]. Линии с максимумами в области 1350, 1490 и $1580 \mathrm{~cm}^{-1}$ обусловлены присутствием в алмазных частицах $s p^{2}$-гибридизованного углерода [12]. Отношение интенсивностей линии алмаза и линий, связанных с $s p^{2}$-гибридизованным углеродом, возрастает с ростом концентрации метана в газовой смеси.

В спектрах ФЛ алмазных частиц на фоне широкой полосы в диапазоне длин волн 500-800 nm наблю-

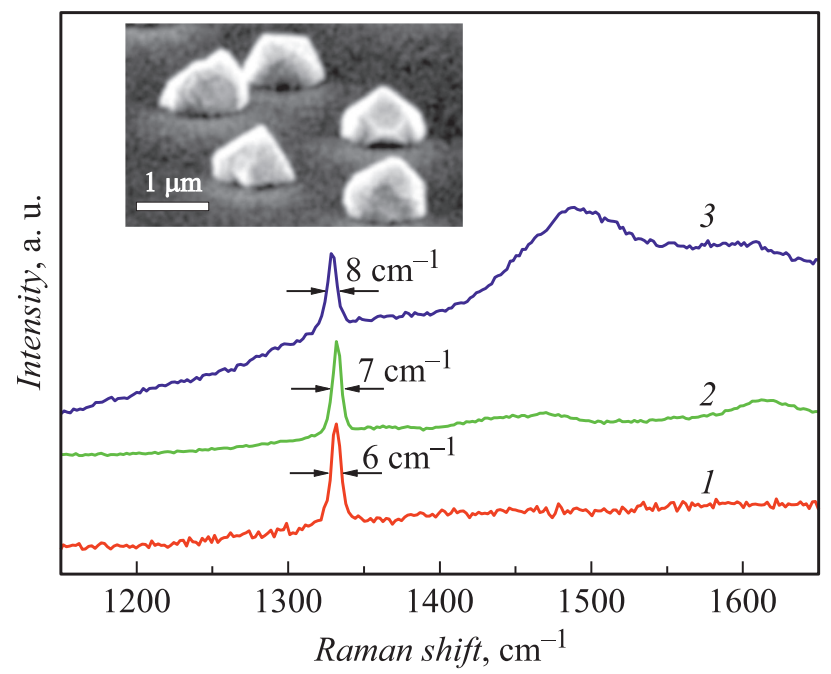

Рис. 1. Спектры комбинационного рассеяния света алмазных частиц, синтезированных при концентрации метана в газовой смеси 2 (1), 4 (2) и 6\% (3). На вставке приведено полученное методом растровой электронной микроскопии изображение алмазных частиц, синтезированных при концентрации метана $4 \%$.

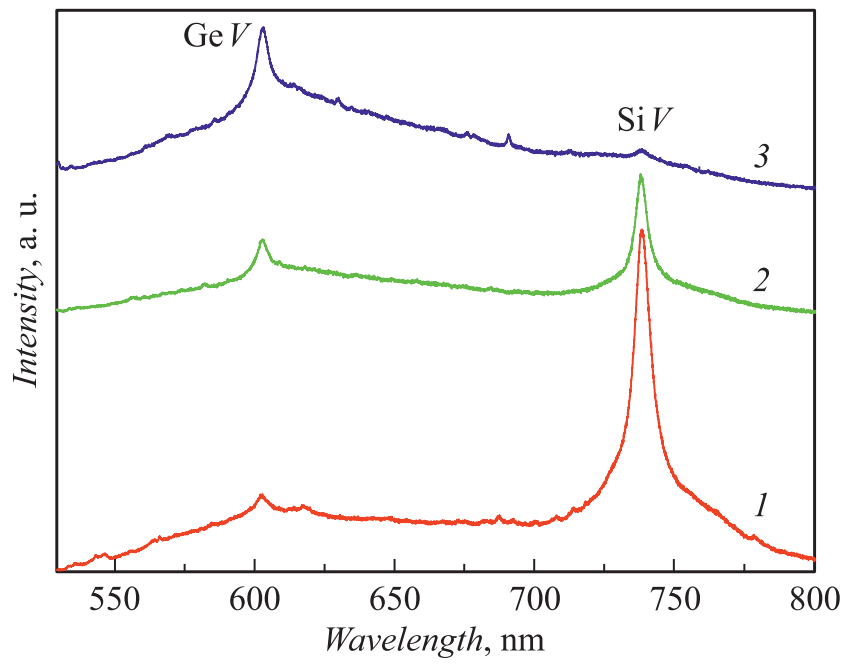

Рис. 2. Спектры фотолюминесценции алмазных частиц, синтезированных при концентрации метана в газовой смеси $2(1)$, 4 (2) и $6 \%(3)$.

даются БФЛ центра Ge $V$ с максимумом на длине волны $602.2 \mathrm{~nm}$ и БФЛ центра $\operatorname{Si} V$ с максимумом на длине волны $738.2 \mathrm{~nm}$ (рис. 2). С увеличением концентрации метана в газовой смеси уменьшается отношение интенсивностей БФЛ центра $\operatorname{Si} V$ и БФЛ центра Ge $V$. Таким образом, вариация концентрации метана в газовой смеси в процессе синтеза алмазных частиц позволяет управлять интенсивностью ФЛ обоих центров окраски.

Приблизительно одинаковая интенсивность БФЛ центров $\mathrm{Ge} V$ и $\mathrm{Si} V$ при достаточно низком содержании $s p^{2}$-гибридизованного углерода наблюдалась в алмазных частицах, синтезированных при концентрации метана в газовой смеси, равной 4\%. Эти алмазные частицы подвергались реактивному ионному травлению, при котором химически активная плазма создавалась с помощью газового разряда $\left(20 \mathrm{vol} . \% \mathrm{O}_{2}+80 \mathrm{vol} . \% \mathrm{~N}_{2} ; 150-250 \mathrm{~W}\right.$ $(2.45 \mathrm{GHz}))[10]$. Время травления контролировалось по методике, изложенной в [13]. Размер алмазных наночастиц, полученных после реактивного ионно-плазменного травления, зависел от длительности процесса травления и находился в диапазоне от 100 до $250 \mathrm{~nm}$.

После травления FWHM линии алмаза сужается с $\sim 7$ до $\sim 3.6 \mathrm{~cm}^{-1}$ (рис. 3, $a$, кривая 2). В спектрах КРС алмазных наночастиц не наблюдаются линии, связанные с присутствием $s p^{2}$-гибридизованного углерода (рис. 3, $a$, кривая 2). В спектрах ФЛ алмазных наночастиц практически отсутствует широкая полоса ФЛ и наблюдаются только интенсивные узкие БФЛ центров окраски Ge $V$ и $\operatorname{Si} V$ (рис. 3, $b$, кривая 2). По-видимому, исчезновение в спектрах широкой полосы ФЛ является следствием удаления в результате реактивного ионного травления областей, содержащих структурные дефекты и $s p^{2}$-гибридизованный углерод. Ширины БФЛ центров $\mathrm{Si} V$ и Ge $V$ для алмазных наночастиц приблизительно равны 6.5 и $6 \mathrm{~nm}$ соответственно. 

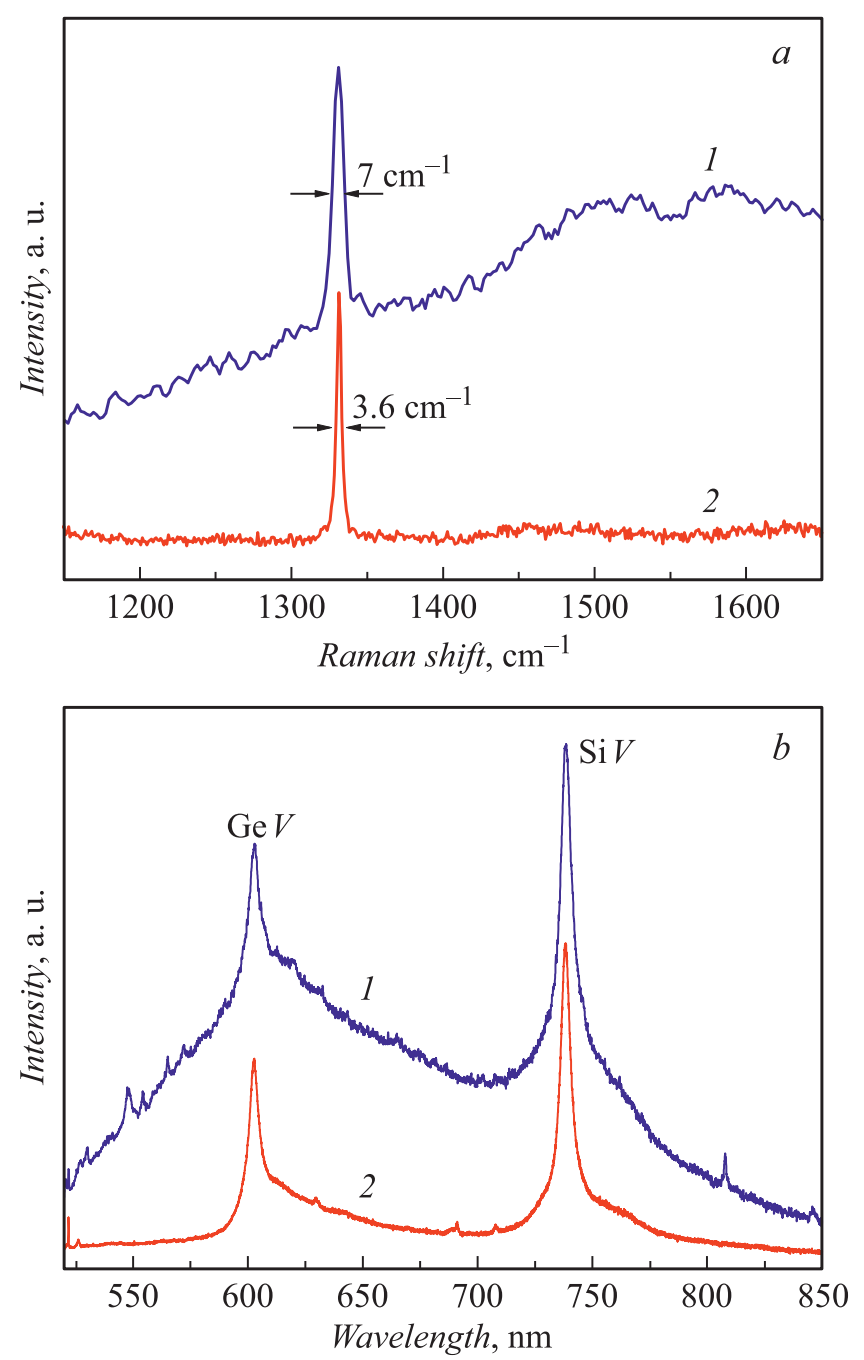

Рис. 3. Спектры комбинационного рассеяния света (a) и фотолюминесценции $(b)$, зарегистрированные до $(1)$ и после $(2)$ реактивного ионно-плазменного травления алмазных частиц.

Таким образом, в работе в результате синтеза методом HFCVD и последующего реактивного ионноплазменного травления получены алмазные наночастицы с двумя центрами окраски ( $\mathrm{Ge} V$ и $\mathrm{Si} V)$. В спектрах ФЛ алмазных наночастиц регистрируются только две интенсивные БФЛ центров $\mathrm{Ge} V$ и $\mathrm{Si} V$. Данные наночастицы могут найти применение в качестве источников двухволнового узкополосного излучения для люминесцентной нанотермометрии, в которой в зависимости от задач или условий проведения измерений может анализироваться эволюция БФЛ как центра $\mathrm{Ge} V$, так и центра $\mathrm{Si} V$.

\section{Благодарности}

Измерения методом растровой электронной микроскопии выполнены с использованием оборудования федерального ЦКП „Материаловедение и диагностика в передовых технологиях“ (ФТИ им. А.Ф. Иоффе).

\section{Финансирование работы}

Работа выполнена с использованием средств госбюджета по теме госзадания 0040-2019-0012.

\section{Конфликт интересов}

Авторы заявляют, что у них нет конфликта интересов.

\section{Список литературы}

[1] Singam S.K., Nesladek M., Goovaerts E. // Nanotechnology. 2020. V. 31. N 10. P. 105501.

[2] Alkahtani M.H., Alghannam F., Jiang L., Rampersaud A.A., Brick R., Gomes C.L., Scully M.O., Hemmer P.R. // Opt. Lett. 2018. V. 43. N 14. P. 3317-3320.

[3] Nguyen C.T., Evans R.E., Sipahigil A., Bhaskar M.K., Sukachev D.D., Agafonov V.N., Davydov V.A., Kulikova L.F., Jelezko F., Lukin M.D. // Appl. Phys. Lett. 2018. V. 112. N 20. P. 203102.

[4] Fan J.W., Cojocaru I., Becker J., Fedotov I.V., Alkahtani M.H.A., Alajlan A., Blakley S., Rezaee M., Lyamkina A., Palyanov Y.N., Borzdov Y.M., Yang Y.P., Zheltikov A., Hemmer P., Akimov A.V. // ACS Photon. 2018. V. 5. N 3. P. 765-770.

[5] Choi S., Agafonov V.N., Davydov V.A., Plakhotnik T. // ACS Photon. 2019. V. 6. N 6. P. 1387-1392.

[6] Alkahtani M., Cojocaru I., Liu X., Herzig T., Meijer J., Küpper J., Lühmann T., Akimov A.V., Hemmer P.R. // Appl. Phys. Lett. 2018. V. 112. N 24. P. 241902.

[7] Alkahtani M.H., Alghannam F., Jiang L., Almethen A., Rampersaud A.A., Brick R., Gomes C.L., Scully M.O., Hemmer P.R. // Nanophotonics. 2018. V. 7. N 8. P. 14231453.

[8] Bradac C., Gao W., Forneris J., Trusheim M.E., Aharonovich I. // Nature Commun. 2019. V. 10. P. 5625 (1-13).

[9] Грудинкин С.А., Феоктистов Н.А., Богданов К.В., Баранов М.А., Баранов А.В., Федоров А.В., Голубев В.Г. // ФТП. 2014. T. 48. B. 2. C. 283-286.

[10] Grudinkin S.A., Feoktistov N.A., Baranov M.A., Smirnov A.N., Davydov V.Y., Golubev V.G. Nanotechnology. 2016. V. 27. N 39. P. 395606.

[11] Феоктистов Н.А., Сахаров В.И., Серенков И.Т., Толмачев В.А., Коркин И.В., Алексенский А.Е., Вуль А.Я., Голубев В.Г. // ЖТФ. 2011. Т. 81. В. 5. С. 132-138.

[12] Prawer S., Nemanich R.J. // Phil. Trans. R. Soc. Lond. A. 2004. V. 362. N 1824. P. 2537-2565.

[13] Grudinkin S.A., Feoktistov N.A., Golubev V.G. // J. Phys.: Conf. Ser. 2019. V. 1400. N 6. P. 066011 (1-7). 